\title{
Effect of photoperiod and melatonin on testicular development in the white-footed mouse, Peromyscus leucopus
}

\author{
L. J. Petterborg and R. J. Reiter \\ Department of Anatomy, The University of Texas Health Science Centre, at San Antonio, \\ 7703 Floyd Curl Drive, San Antonio, Texas 78284, U.S.A.
}

\begin{abstract}
Summary. At autopsy the absolute and relative testicular weights of 6-week-old white-footed mice were significantly lower $(P<0.001)$ in animals exposed to a short photoperiod $(8 \mathrm{~L}: 16 \mathrm{D})$ or exposed to a long photoperiod $(16 \mathrm{~L}: 8 \mathrm{D})$ and treated with a $1 \mathrm{mg}$ melatonin s.c. implant than in those kept only in a long photoperiod. The long photoperiod animals had testes of normal appearance and complete spermatogenesis, but there had been little development in the testes of the other animals and seminiferous tubule diameters were reduced.
\end{abstract}

\section{Introduction}

The seasonal change in daylength provides a reliable cue for the regulation of reproduction in many species. The involvement of the pineal gland in the mediation of photoperiodic phenomena is well known (Reiter, 1978).

Photoperiod has been shown to have significant effects on various aspects of the biology of the white-footed mouse, Peromyscus leucopus (Whitaker, 1940; Quay, 1956; Lynch, 1973). Mice kept in less than $12 \mathrm{~h}$ light/day are less fertile than animals maintained in long photoperiods. Quay (1956) has suggested that the pineal gland of $P$. leucopus is responsive to photoperiod; pineal glands from mice maintained in darkness appeared to be more active (based on morphological criteria) than those from animals kept under increasing daylength. Melatonin is produced in the pineal gland when animals are subjected to alternating periods of light and darkness (Moore, 1978; Rollag, Chen, Ferguson \& Reiter, 1979). Subcutaneous melatonin implants have been shown to have inhibitory effects on the reproductive systems of adult short-tailed weasels (Rust \& Meyer, 1969) and white-footed mice (Lynch \& Epstein, 1976). Since the effect of photoperiod may be mediated through pineal melatonin, we have examined the morphological effects of photoperiod and melatonin on the reproductive system of male white-footed mice.

\section{Materials and Methods}

The white-footed mice (Peromyscus leucopus) used in this study were derived from a colony begun with 8 pairs provided by G. Robert Lynch, Wesleyan University, Middletown, Connecticut. Males entered the study at weaning, at approximately 3 weeks of age, and 3 treatment groups were established: Group 1 contained animals kept in a long photoperiod of $16 \mathrm{~h}$ light : $8 \mathrm{~h}$ dark; the animals in Group 2 were kept in a short photoperiod of $8 \mathrm{~h}$ light : $16 \mathrm{~h}$ 
dark; and the animals in Group 3 were kept in a long photoperiod and treated with melatonin. In addition, animals (Group 4) were killed at weaning and their testes removed and weighed. Groups 1 and 3 were maintained in a light- and temperature $\left(23 \pm 1{ }^{\circ} \mathrm{C}\right)$-controlled room, while Group 2 was housed in a light-proof cabinet where photoperiod ( $8 \mathrm{~h}$ light:16 h dark) and temperature $\left(23 \pm 1^{\circ} \mathrm{C}\right)$ were also regulated. Animals were caged no more than 5 per cage and provided with food (Wayne Lab-Blox) and water ad libitum.

Melatonin implants were prepared by mixing crystalline melatonin (Sigma) with beeswax as previously described (Reiter, Vaughan, Blask \& Johnson, 1974). Each pellet contained $1 \mathrm{mg}$ melatonin and $24 \mathrm{mg}$ beeswax. The resulting pellets were implanted under the skin along the dorsal midline through a small incision.

At weaning, each animal was anaesthetized with methoxyflurane (Metofane: PitmanMoore), weighed and total length measurements were taken. The melatonin implants were inserted in Group 3 animals ( $1 /$ mouse) at this time. The males in each treatment group were killed after 3 weeks and were measured and weighed again. The testes were removed and weighed and then fixed in Bouin's fluid, dehydrated with ethanol, embedded in paraffin wax, sectioned at $5 \mu \mathrm{m}$, and stained with haematoxylin and eosin. Twenty seminiferous tubule diameters were measured in each of 3 testes from each of the treatment groups.

The results were statistically compared by a one-way analysis of variance followed by a $t$ test for differences among multiple means.

\section{Results}

As shown in Table 1, there were no significant differences in gross body measurements among the treatment groups, but absolute and relative testicular weight was significantly depressed in Groups 2 and $3(P<0.001)$.

Table 1. Mean ( \pm s.e.m.) measurements of 3-week-old weanling mice (Group 4) and whitefooted mice raised under long (Group 1) or short (Group 2) photoperiods or under a short photoperiod and treated with melatonin (Group 3)

\begin{tabular}{|c|c|c|c|c|}
\hline & $\begin{array}{l}\text { Group 1 } \\
(N=21)\end{array}$ & $\begin{array}{c}\text { Group 2 } \\
(\mathrm{N}=13)\end{array}$ & $\begin{array}{l}\text { Group } 3 \\
(\mathrm{~N}=11)\end{array}$ & $\begin{array}{c}\text { Group } 4 \\
(N=10)\end{array}$ \\
\hline \multicolumn{5}{|l|}{ Body wt (g) } \\
\hline At weaning & $11 \cdot 3 \pm 0 \cdot 2$ & $11.7 \pm 0.4$ & $11.7 \pm 0.4$ & \\
\hline At autopsy & $20 \cdot 0 \pm 0.5$ & $18.4 \pm 0.5$ & $17.8 \pm 0.7$ & $11.9 \pm 0.3$ \\
\hline \multicolumn{5}{|l|}{ Total length (mm) } \\
\hline At weaning & $143.6+1.6$ & $142 \cdot 6+2 \cdot 7$ & $147.8+1 \cdot 8$ & \\
\hline At autopsy & $168.2+1.6$ & $168.8+2.2$ & $167.0 \pm 1.9$ & $146 \cdot 7+1 \cdot 6$ \\
\hline \\
\hline $\mathrm{mg}$ & $152 \cdot 0 \pm 8 \cdot 1$ & $63 \cdot 1 \pm 8 \cdot 4^{*}$ & $45 \cdot 0 \pm 10 \cdot 1^{*}$ & $27 \cdot 6 \pm 2 \cdot 1$ \\
\hline $\mathrm{mg} / \mathrm{g}$ body wt & $7.6 \pm 0.3$ & $3.4 \pm 0.4^{*}$ & $2.5 \pm 0.5^{*}$ & $2.3 \pm 0.1$ \\
\hline \multicolumn{5}{|l|}{ Seminiferous tubule } \\
\hline diam. $(\mu \mathrm{m})$ & $142 \pm 2 \cdot 2$ & $90 \cdot 5 \pm 1 \cdot 4$ & $74 \cdot 5 \pm 1 \cdot 2$ & - \\
\hline
\end{tabular}

* $P<0.001$ compared to Group 1 .

\section{PLATE 1}

Fig. 1. Testis from a white-footed mouse in Group 1 (long photoperiod). $\times 350$.

Fig. 2. Testis from a white-footed mouse in Group 2 (short photoperiod). $\times 350$.

Fig. 3. Testis from a white-footed mouse in Group 3 (melatonin implant). $\times 350$. 


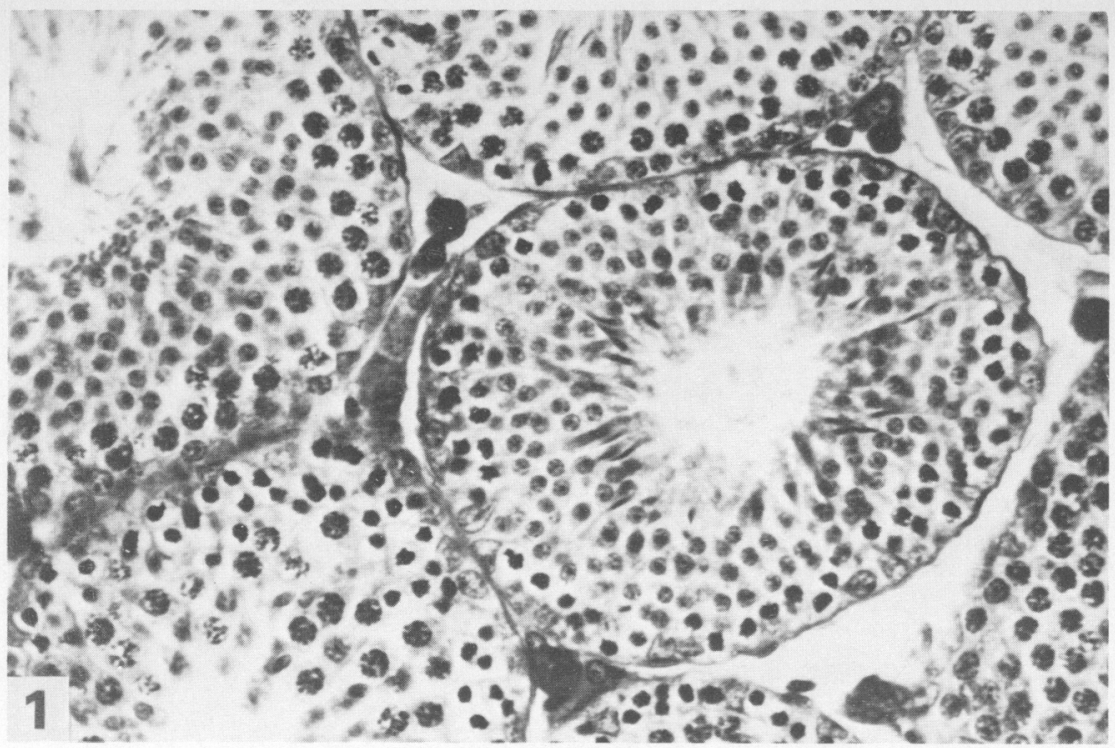

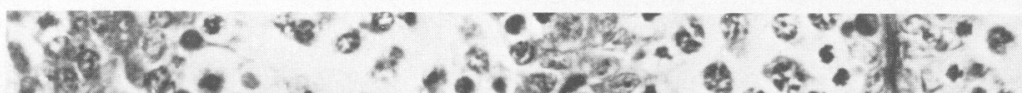

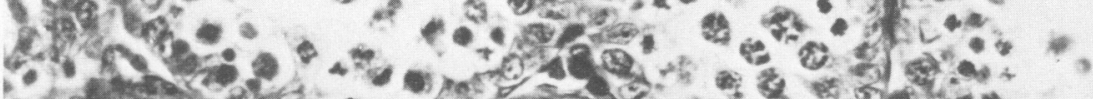

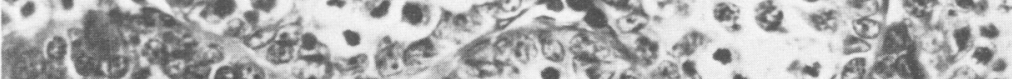

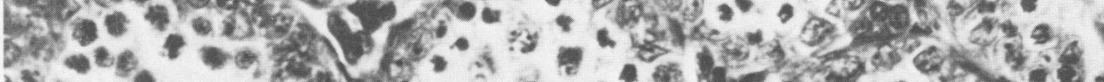

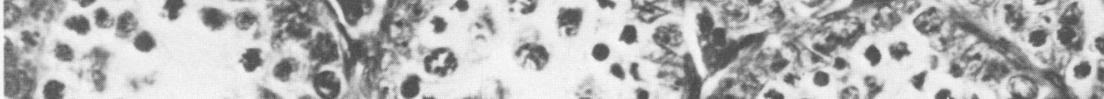

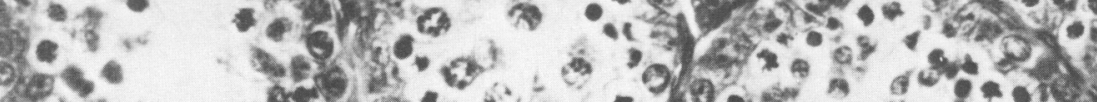

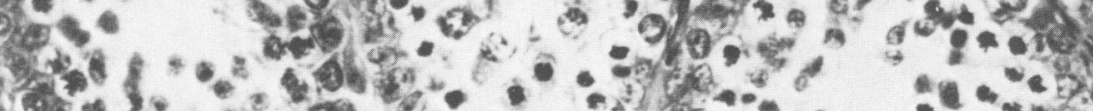

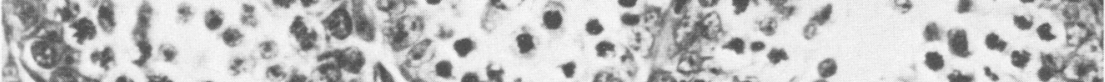

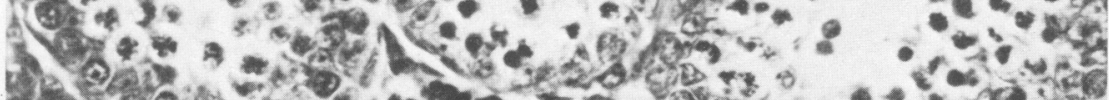
3. 2 -

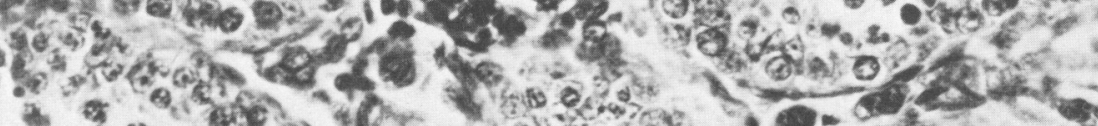

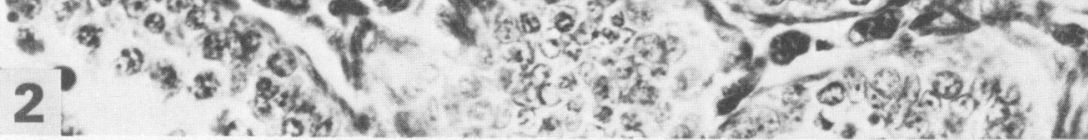

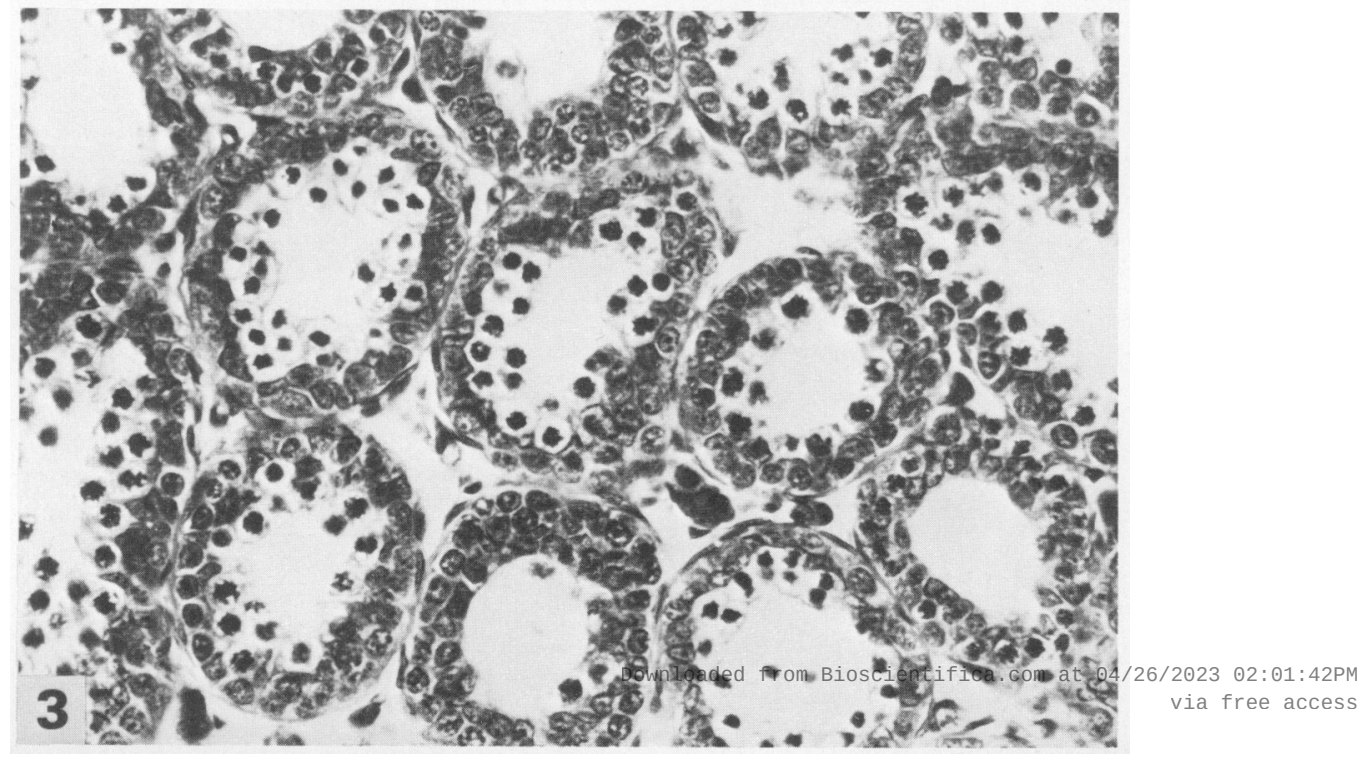


Histological examination revealed that seminiferous tubular diameter (Table 1) was greater in the testes of Group 1 mice (Pl. 1, Fig. 1), than in those of Group 2 (Pl. 1, Fig. 2) or Group 3 (Pl. 1, Fig. 3) animals. Complete spermatogenesis was evident in Group 1 animals whereas only Sertoli cells, stem cells and limited numbers of spermatocytes were observed in males in Groups 2 and 3. Judging from the measurements that were made, the testes of the melatonin-treated mice (Group 3) appeared to be the least well developed of the two repressed groups.

\section{Discussion}

The results of this study clearly demonstrate the similar repressive effects of both short photoperiod and melatonin on the sexual development of young male white-footed mice. The control of reproduction by photoperiod is thought to be the result of an increase in the activity of the pineal gland as a consequence of darkness with the concomitant synthesis and release of a chemical intermediary. While it is necessary to demonstrate equivalence in the effects of photoperiod and the presumed mediator of those effects, this is not sufficient evidence for melatonin to be designated the hormone responsible for darkness-induced retardation of sexual development. Other pineal compounds such as arginine vasotocin and 5-methoxytryptophol share antireproductive properties with melatonin (Reiter \& Vaughan, 1977).

The inhibitory effect of photoperiod on reproduction in the adult white-footed mouse has been shown by Lynch (1973) who determined gonadal status by palpation and examination of the external genitalia over an $11 \frac{1}{2}$ week period. The present study utilized immature animals to assess the gross and microscopic differences between the treatments in an experiment of relatively short duration, but significant inhibition of testicular development did occur during this time. Johnston \& Zucker (1979) have reported that development of the reproductive system was retarded in cotton rats (Sigmodon hispidus) raised in $10 \mathrm{~h}$ light: $14 \mathrm{~h}$ dark; seminal vesicle and testicular weights were reduced but spermatogenesis was not affected.

Lynch \& Epstein (1976) observed regression of the reproductive system in 3-month-old white-footed mice given melatonin implants. Similarly, melatonin from a melatonin-beeswax implant has been shown to inhibit reproductive development in adult male weasels (Rust \& Meyer, 1969), Djungarian hamsters (Hoffman, 1973) and young male rats (Sorrentino, Reiter \& Schalch, 1971). The maximal daily dosage of melatonin to which the animals in the present study could have been exposed was $45-50 \mu \mathrm{g}$. However, it is unlikely that the entire $1 \mathrm{mg}$ melatonin was dissolved from the beeswax during the 21-day period, and the daily dosage was probably much less. Juvenile white-footed mice are very sensitive both to melatonin implants and short photoperiod exposure, while Syrian hamsters are sensitive to photoperiod only when adults (Reiter, 1968, Turek, 1979).

This work was supported by NSF grant no. PSM 77-05734 and a Sigma Xi Grant-in-Aid of Research.

\section{References}

Hoffmann, K. (1973) The influence of photoperiod and melatonin on testis size, body weight, and pelage colour in the Djungarian hamster. (Phodopus sungorus). J. comp. Physiol. 85, 267-282.

Johnston, P.G. \& Zucker, I. (1979) Photoperiodic influences on gonadal development and maintainence in the cotton rat, Sigmodon hispidus. Biol. Reprod. 21, 1-8.

Lynch, G.R. (1973) Effect of simultaneous exposure to differences in photoperiod and temperature on the seasonal molt and reproductive system of the white-footed mouse, Peromyscus leucopus. Comp. Biochem. Physiol. 44A, 1373-1376.

Lynch, G.R. \& Epstein, A.L. (1976) Melatonin induced changes in gonads, pelage, and thermogenic characters in the white-footed mouse, Peromyscus leucopus. Comp. Biochem. Physiol. 53C, 67-68.

Moore, R.Y. (1978) The innervation of the mammalian 
pineal gland. In The Pineal and Reproduction, pp. 1-29. Ed. R. J. Reiter. Karger, Basel.

Quay, W.B. (1956) Volumetric and cytological variation in the pineal body of Peromyscus leucopus (Rodentia) with respect to sex, captivity and day-length. $J$. Morph. 98, 471-495.

Reiter, R.J. (1968) The pineal gland and gonadal development in male rats and hamsters. Fert. Steril. 19, 1009-1017.

Reiter, R.J. (1978) Interaction of photoperiod, pineal and seasonal reproduction as exemplified by findings in the hamster. Prog. Reprod. Biol. 4, 169-190.

Reiter, R.J. \& Vaughan, M.K. (1977) Pineal antigonadotrophic substances: polypeptides and indoles. Life Sciences 21, 159-172.

Reiter, R.J., Vaughan, M.K., Blask, D.E. \& Johnson, L.Y. (1974) Melatonin: its inhibition of pineal antigonadotrophic activity in male hamsters. Science, N.Y. 185, 1169-1171.
Rollag, M.D., Chen, H.J., Ferguson, B.N. \& Reiter, RJ. (1979) Pineal melatonin content throughout the hamster estrous cycle. Proc. Soc. exp. Biol. Med. 162, 211-213.

Rust, C.C. \& Meyer, R.K. (1969) Hair color, molt, and testis size in male short-tailed weasels treated with melatonin. Science, N.Y. 165, 921-922.

Sorrentino, S., Reiter, R.J. \& Schalch, D.S. (1971) Hypotrophic reproductive organs and normal growth in male rats treated with melatonin. J. Endocr. 51, 213-214.

Turek, F.W. (1979) Effect of melatonin on photicindependent and photic-dependent testicular growth in juvenile and adult male golden hamsters. Biol. Reprod. 20, 1119-1122.

Whitaker, W.L. (1940) Some effects of artificial illumination on reproduction in the white-footed mouse, Peromyscus leucopus noveboacensis. J. exp. Zool. 83, 33-59. 